\title{
The Logic of the Doodles in Finnegans Wake II.2
}

\author{
Sangam MacDuff
}

\begin{abstract}
This paper considers the doodles in the "Nightlessons" chapter of Finnegans Wake, such as the geometrical figure on page 293, the childish drawings that close the chapter, and Issy's "Doodles family" footnote ( FW 299 F4). Since Roland McHugh's Sigla of Finnegans Wake, the symbols Joyce developed to refer to his protean and manifold characters have often been regarded as a key to the novel. However, the resemblance between Joyce's sigla and the symbols of formal logic has not been noted. For instance, HCE's siglum, as it appears on $F W 36.16$ (“ $\exists !$ !), is identical to Russell's non-empty set, a forerunner of the existential quantifier; ALP's delta $(\Delta)$ is a common mathematical symbol; and Issy's siglum, in two of its aspects $(\vdash, \perp)$, represents, respectively, Frege's assertion sign and Peirce's notation for nor. Joyce drew on Russell's Introduction to Mathematical Philosophy (1919) for "Nightlessons", and in Tales Told of Shem and Shaun (1929), where the "triangle" section of II.2 was first published, C.K. Ogden compares the language of the Wake to formal logic. These sources, and the way Joyce introduced the sigla into the published text, suggest that both the art and the logic of Joyce's "Doodles family" are informed by mathematical philosophy.
\end{abstract}

\section{Keywords}

Finnegans Wake - Logic - Mathematics - Doodles - Bertrand Russell - Sigla - Euclid

In his early essay, "The Study of Languages" (c.1898-99), Joyce stresses that "the most important study for the mind is Mathematics": his "vindication of Literature will never venture to put it before Mathematics in that respect" ( $C W_{2} 6-$ 27). Since mathematics and science formed the core of the revised Jesuit curriculum, ${ }^{1}$ Joyce's qualified defence of literature might be read as an ironic show of deference towards his masters' pedagogical principles, but it would be misleading to suppose that Joyce is ironically inverting the roles of literature

1 Kevin Sullivan, Joyce among the Jesuits (New York: Columbia University Press, 1958), 83-84. 
and mathematics, because from the opening lines of the essay, he undermines the distinction between them.

Joyce begins "The Study of Languages" with an allusion to Lippo Memmi's allegory of "the seven earthly Sciences" in the church of Santa Maria Novella in Florence (Figure 12.1). Derived from Aquinas's Summa Theologiae, this fresco, usually attributed to Andrea di Bonaiuto, personifies the earthly sciences - or Liberal Arts - as women:

Reading from right to left, the first is the 'Art of Letters' and the seventh 'Arithmetic'. The first is oftener called Grammar, because it refers more directly to that branch of 'Letters'. Now the artist's idea in this arrangement was to show the gradual progress from Science to Science, from Grammar to Rhetoric, from Rhetoric to Music and so on to Arithmetic. In selecting his subjects he assumes two things. First he assumes that the primary science is Grammar, that is, that science which is the first and most natural one to man, and also that Arithmetic is the last, not exactly as the culmination of the other six, but rather as the final, numbered expression of man's life. Secondly, or perhaps first, he assumes that Grammar, or Letters, is a science. His first assumption classes, if it does nothing more, Grammar and Arithmetic together as the first and last things in human knowledge. ( $C W$ 25)

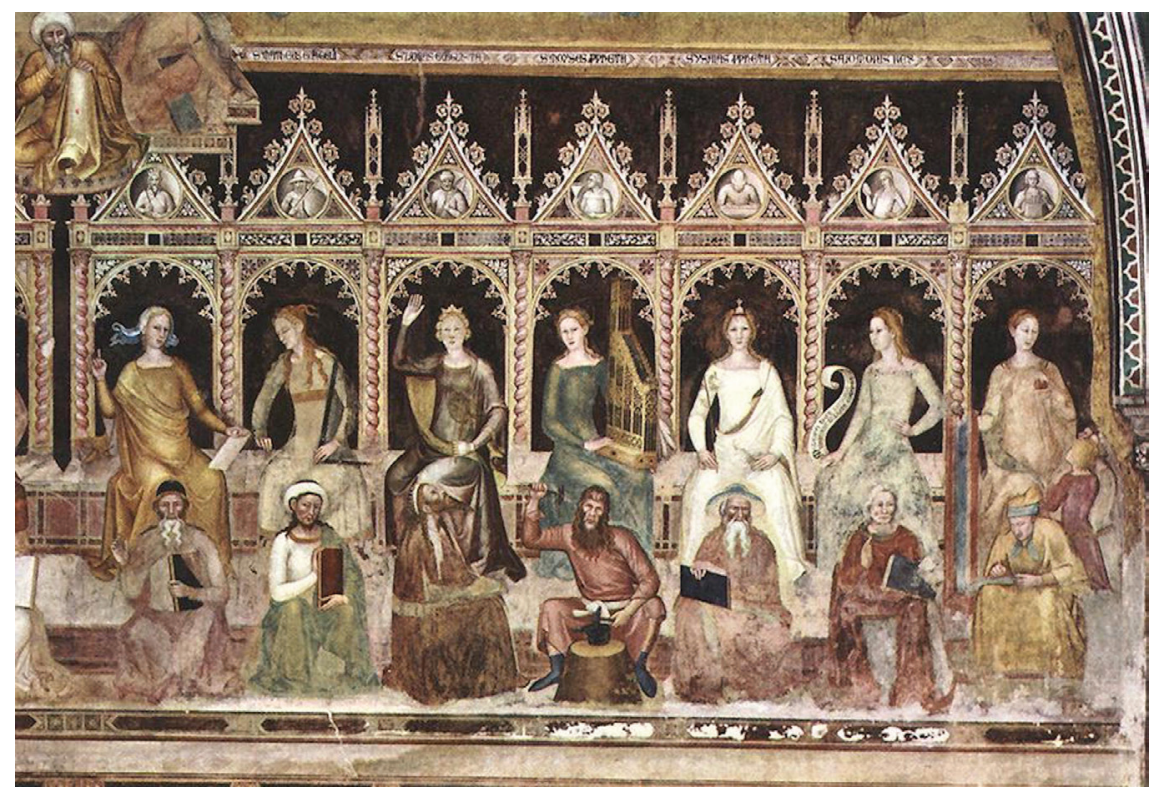

FIGURE 12.1 Andrea di Bonaiuto, Allegory of the Liberal Arts, 1365-68, fresco, Cappella Spagnuolo, Santa Maria Novella, Florence 
Joyce proceeds to argue that not only in its grammar, but also in its "Characters", literature is "at the root a science" (26). Given the privilege accorded to mathematical studies in Jesuit education, it is not surprising that he should have chosen to defend literature as a science, but since the fresco is often referred to as an allegory of the Liberal Arts, he could equally well have claimed Arithmetic, Geometry and Astronomy (read left to right) as arts. The point is that there is no "stern demarcation" between literature and mathematics:

as Mathematics and the Sciences of Numbers partake of the nature of that beauty which is omnipresent, which is expressed, almost noiselessly, in the order and symmetry of Mathematics, as in the charms of literature; so does Literature in turn share in the neatness and regularity of Mathematics.

$C W 26$

This connection between literature and mathematics has important repercussions in Joyce's work, beginning with the strange words paralysis, gnomon and simony on the opening page of Dubliners. The boy in "The Sisters" has learnt "gnomon" from Euclid, and Joyce most likely drew the word directly from Euclid's Elements, since he was examined on Euclid for four years at Belvedere and twice more at University College Dublin. ${ }^{2}$ But he may also have encountered it in Bonaiuoto's fresco, where the figure of Geometry, with Euclid at her feet, holds a set square, or gnomon. ${ }^{3}$ The gnomon in Dubliners has been seen as the figure of something missing, a gap to be filled, as a model or synecdoche for a fiction without wholeness, as a reiterative procedure, or even as a symbol

2 According to Morris Kline, Euclid had a central role in Jesuit education because he was regarded as "the progenitor of the science of logic" (Mathematics in Western Culture [London: Oxford University Press, 1953], 55, qtd. in Thomas Jackson Rice, Joyce, Chaos, and Complexity [Urbana; Chicago: University of Illinois Press], 37).

3 Joyce's attention to Bonaiuto is clear from the opening of the essay. Joyce also notes that in the figure of Rhetoric in Santa Maria's church "Truth is seen reflected in a Mirror" ( $C W_{27-28}$; see the inset medallion above Rhetoric, second from the right in Figure 12.1). Immediately after, Joyce questions the Aristotelian doctrine that "true oratory" can support false conclusions ( $C W 28$ ), possibly alluding to Dialectic in Bonaiuto's fresco (third from the right), where Aristotle holds a branched stick, representing the syllogism, and a scorpion-tailed dilemma. The connection between Aristotle, Euclid and Joyce's "Study of Languages" is far-reaching: as Rice argues, "Joyce's schooling in Euclidean geometry, even more than his training in scholastic argumentation, taught him to value the syllogistic method as a structure for rational thought, the logical model that Euclid appropriated from Aristotle's Posterior Analytics and passed on to Aquinas" (24). 
of accretion - but virtually all commentators agree that in its Euclidean, geometrical sense, it offers a key to the poetics of Joyce's stories. ${ }^{4}$

Book II, chapter 2, the "Nightlessons" chapter of Finnegans Wake, also pivots around a geometrical problem, as Shem teaches Shaun how to construct an equilateral triangle using only a ruler and a pair of compasses. This involves:

1) marking the points $\alpha$ and $\lambda$ ( $F W 287.14-15,29.318-294.4)$;

2) drawing a line between them $(F W$ 294.2-3);

3) drawing two circles centred on these points ( $F W 294.8-10,295.18-21)$;

4) marking P and $\pi(F W$ 296.6-10)

5) connecting the points $(F W 296.24-27)$ to complete the diagram printed on page 293:

If the exercise seems familiar, that is because it is the first problem in Euclid's Elements. I was given the same problem in my first year of secondary school, aged 11 or 12, and Joyce would almost certainly have tackled it at a similar age, for as we have seen, mathematics and science were at the core of the revised Jesuit ratio studiorum of 1832, where Euclid had a central place. Despite his Jesuit training, however, critics have assumed that Joyce was neither good at

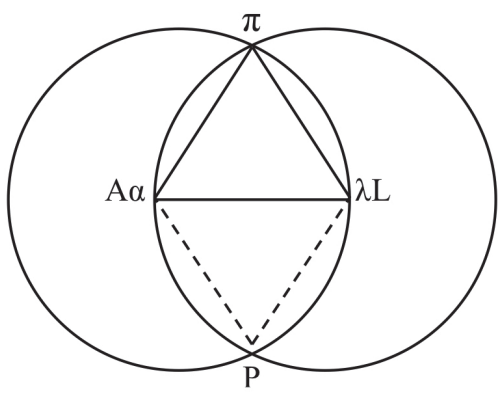

FIGURE 12.2

Euclidean figure, Finnegans Wake, 293

4 Margot Norris derives the word from "model", arguing that "The Sisters" is "the gnomon of the book", because its "gaps and silences" serve "as a synecdoche for a collection of fictions without wholeness" (Suspicious Readings of Joyce's Dubliners [Philadelphia: University of Pennsylvania Press, 2003], 18). Numerous critics have interpreted the gnomon as "The Figure with Something Missing, The Gap to Be Filled", but Fritz Senn argues that it is also an accretive symbol: "if you take one parallelogram and join a smaller one to its corner (with parallel sides) you get the same result: a construction of both and" ("Gnomon Inverted", in Rosa Maria Bollettieri Bosinelli, ed. ReJoycing: New Readings of Dubliners [Lexington: Kentucky University Press, 1998], 249-50). Senn's geometry is slightly askew (think of a square), but his point holds for the logic of Dubliners, where figures of absence, from ellipses and euphemisms to fathers and phantoms, come to define the very stories that would seem incomplete without them. 
mathematics nor interested in it. ${ }^{5}$ Their assumption is supported by the fact that Joyce did spectacularly badly in his Euclid and Trigonometry exams in the final year at Belvedere (40/600 and 20/700, respectively). However, prior to that, Joyce performed better in arithmetic than English for three consecutive years (in percentage terms), and his highest ever examination score was for arithmetic. ${ }^{6}$ He also got better marks in Euclid than English in his first year at Belvedere, when he was examined on Book 1 of Euclid, which includes the very problem Shem teaches Shaun. Of course, Euclid's first problem is straightforward, making Shaun's inability to follow the demonstration comical, ${ }^{7}$ but later in the triangle section of II.2, Joyce mentions more complex mathematical functions, such as limits and logarithms, so it is worth emphasising that Joyce can't have been too bad at maths if he did better in algebra than English the same year he won first prize for English composition in the whole of Ireland.

It is impossible to know which edition of Euclid Joyce used, but in II.2, at least, the differences are insignificant. Joyce alludes to three editions in "Nightlessons": "Casey's frost book" ( $F W$ 286.o9) combines John Casey's First Six Books of the Elements of Euclid (1890) with Percival Frost; "doddhunters" (FW 283.25-26) and "toadhauntered" ( $F W 293$ F2) refer to Isaac Todhunter, who published The Elements of Euclid in 1869; and "O dee, O dee" ( $F W$ 299.21) is an allusion to John Dee, a Renaissance magus and mathematician said to have

5 Kevin Sullivan claims that Joyce's "lack of interest in mathematics" is "revealed in his examination" of 1896-97 (104): mathematics and natural philosophy were "subjects of no interest to Joyce" (160). That Sullivan was wrong about Joyce's interest in science has been amply demonstrated, but Joyce's interest in mathematics is less well documented, and even critics who consider this question (e.g., Salvadori and Schwartzman, McCarthy, Livingstone) tend to perpetuate Sullivan's erroneous assumption. A notable exception is Ray Mines's and Reed Way Dasenbrock's “'Nought Nowhere Was Never Reached': Mathematics in 'Ulysses'". James Joyce Quarterly 35.1 (Fall 1997): 25-36, which provides the best discussion of Joyce's mathematics.

6 Since the number of marks available differed from one examination to another, I have compared his scores in percentage terms, rather than raw marks. For Joyce's exam results, see Sullivan 236-40; JJ 751, 752, 756; Neil R. Davison, "Joyce's Matriculation Examination", James Joyce Quarterly 30.3 (Spring 1993): 393-407.

7 Shaun's apparent dullness may conceal a more serious point. Ciaran McMorran contends that Kev's (Shaun's) wrath towards Dolph (Shem) is not caused by incomprehension, but exasperation that his brother cannot see his own, non-Euclidean interpretation of the problem (Geometry and topography in James Joyce's Ulysses and Finnegans Wake, PhD thesis, University of Glasgow, 2016: <http://theses.gla.ac.uk/7385/> [accessed 2 April 2019] 64-78). Given the references to Newtonian mechanics and Einstein's relativity theory (which draws on Riemann's non-Euclidean geometry), McMorran's thesis is convincing. Similarly, I believe that in contrast to Newton's calculus of fluxions ( $F W$ 297.29), Joyce's numerous allusions to limits in I.5 and II.2 allude to Richard Dedekind's and Karl Weierstrass's rigorous definition of mathematical limits (in terms of $\delta-\varepsilon$ ), although it would take another essay to demonstrate. 
inspired Shakespeare's Prospero. The allusion to Dee at the culmination of the triangle section echoes three exclamations earlier in the section ("O, dear me": $F W$ 294.11-12, 295.25), which may suggest that, just as Dee attempted to create a universal symbol in Monas Hyrogliphica (Figure 12.3), Joyce plays with the same idea in $A L P$ 's inscribed $\Delta$.

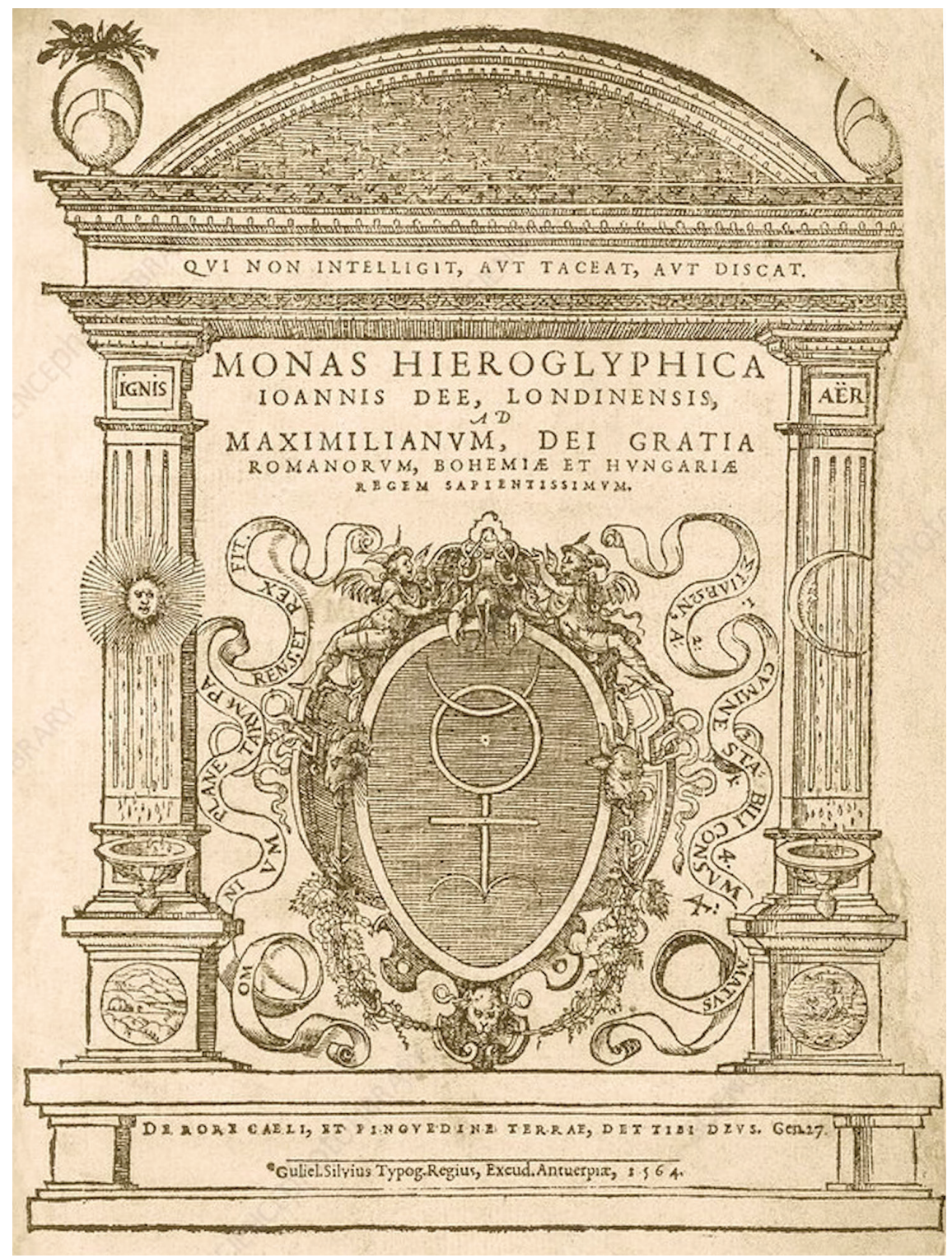

FIGURE 12.3 John Dee, Monas Hieroglyphica, Antwerp: John Silvius, 1564, title page 
John Dee is also relevant because he wrote an influential preface to Henry Billingsley's first English translation of The Elements. Naturally, each of these editions includes a similar diagram for Euclid's first problem, although all three versions include only the upper triangle. By joining $\alpha$-P and P-L with dotted lines ("join alfa pea and pull loose by dotties": $F W$ 296.24-25), Joyce multiplies the symbolic possibilities. "I'll make you to see figuratleavely the whome of your eternal geomater [earth-mother]", Shem tells Shaun, representing the twins' origins (who me?) in the womb or home of their maternal geometer (lit. earth-measure). Beginning with "Anny liffle [Liffey] mud" from their "mut" (mother/courage: $F W 287 \cdot 5^{-7}$ ), Shem ends by inverting the triangle to depict ALP's pudenda as a "muddy old triagonal delta" ( $F W$ 297.24; cf. $F W$ 297.9, 26-279). Roland McHugh points out that this central segment with the two triangles forms the mystical figure of "the Vesica Piscis, or fish's bladder", symbolizing the womb, the Evil Eye, Christ's wounds and the Virgin Mother. ${ }^{8}$ Superimposed, the triangles illustrate Solomon's seal, whose mystical and theosophical significance Joyce alludes to $(F W$ 297.3-4; see Sigla 70-71). Combined with the overlapping circles, which are compared to eggbeaters and gyres ("Gyre O, gyre O, gyrotundo" [ $F W 295.23-24]$ ), the inverted triangle section and the figure as a whole - allows for an extraordinary range of interpretation, from the uterine and perineal regions ("its nether nadir is vortically where ... its naval's napex will have to beandbe" $[F W$ 297.12-14]) to Dublin and environs ("Vieus Von DVbLIn...", FW 293.12-16), the poles of the earth, ${ }^{9}$ Dante's empyrean and infernal realms, ${ }^{10}$ Madame Blavatsky's "Chaldeo-Jewish cosmogony",11 and an all-encompassing Yeatsian vision. ${ }^{12}$ Thus, the figure is presented as a truly universal symbol, like John Dee's Monas Hieroglyphica, in which, on one level, the "muddy old triagonal delta" of earth and river, uterus and vagina is "Mother of us all!" ( $F W$ 299.3), and on another, the solid lines that compose the Euclidean triangle are "sparematically logoical" ( $F W$ 296.26), representing the "semenal rations" ( $F W 296.04)$ or seminal ratios/reasons that, in conception, at least, give rise to the spermatikoi logoi, or seeds of all things.

8 Roland McHugh, The Sigla of Finnegans Wake (London: Edward Arnold, 1976), 68.

9 Katarzyna Bazarnik, Joyce \& Liberature (Prague: Litteraria Pragensia, 2011),155, qtd. in McMorran, 74.

10 McHugh, Sigla, 69; Jonathan McCreedy, “'Ocone! Ocone!': ALP’s ${ }_{3} D$ Siglum and Dolph's 'Dainty' Diagram", Genetic Joyce Studies 11 (2011), <http://www.geneticjoycestudies.org/> [accessed 2 April 2019]; McMorran, 73 .

11 McHugh, Sigla, 68.

12 McHugh, Sigla, 72-73; Carla Baricz, "The Finnegans Wake Diagram and Giordano Bruno", Joyce Studies Annual (2008), 235-42. 
At the centre of the figure is a diamond, or parallelogram, like the original figure from which a gnomon is cut, and just as the gnomon in Dubliners is a figure for the collection, so too the Euclidean diagram in II.2 can be seen as a figure for the poetics of Finnegans Wake. If the gnomon is a figure of absence and accretion, the mirrored triangle is a figure of origins and doubling - both the maternal origins of the twins and the mirroring of the $\Delta$. Like the inhabitants of Dublin, Georgia, "doubling their mumper all the time" (FW 3.8-9), in the Wake people, places, times and spaces are constantly doubling. Indeed, the doubling of meaning through repetition and variation is central to Wakean language - and language per se. Thus, the double- $\Delta$ figure symbolises a tendency towards universal significance, but if every symbol reiterates the same structure, their constant proliferation undercuts any claim to totality, so that each is simultaneously empty and universal, creating the divine comedy of the Wake.

This symbolic logic means that the originary doubling of the triangle can be read in Derridean terms as the play of différance and supplementarity in the chain of signifiers, ${ }^{13}$ but at the same time, the diagram in "Nightlessons" is about limits and boundaries. Figuratively, it begins with marking the earth, an act of inscription (the original meaning of "character") that seems to summon the voice of ALP in a five-page parenthesis (ostensibly mediated through Shem as "Dolph" [FW 286.25, 287.18]) that divides the chapter in two. The parenthesis itself begins with three parentheses, the third in Latin, ending "everything recognizes itself through something opposite" ( $F W$ 287.26-27, trans. McHugh), and after another such parenthesis, marked by long dashes, the monologue ends "you must, how, in undivided reawlity draw the line somewhawre" ( $F W$ 292.31-32), followed by a close bracket which graphically represents the curve Dolph must draw with his compass, and thus links the interlude to the diagram which appears on the adjacent page (itself in brackets).

This is clearer in the first draft, where the geometrical figure appears after Dolph's "you must draw the line somewhere" (JJA 53:4). ${ }^{14}$ Joyce added the long parenthesis in the second draft (JJA 53: $36-41)$, linking it back to the lesson by closing the digression with "draw the line somewhawre" ( $F W$ 292.32). This strengthens the connection to Dolph, leaving no doubt that the last remark, and the closing bracket, look forward to the diagram, despite the echoing voices within the parenthesis. In fact, Dolph's demonstration continues for another

13 Jacques Derrida, Dissemination, trans. Barbara Johnson (Chicago: Chicago University Press, 1981), 156-236. For a brilliant account of Derrida's "infrastructures" and the notion of "originary doubling", see Rodolphe Gasché, The Tain of the Mirror: Derrida and the Philosophy of Reflection (Cambridge: Harvard University Press, 1986), 185-239. 
three pages, so that it would seem more logical to insert it after $F W$ 296.27. Yet Joyce's placement of the diagram, close to the parenthetical drawing of the line, is as logical as the Euclidean figure itself, for it connects the central symbol to the "drawings on the line" that close the chapter and the symbolic logic of Issy's "Doodles" ( $F W$ 308.F2, 299.F4).

We can trace this connection through the drafts. Joyce drew several versions of the Euclidean diagram, but from the second draft, where he added the dotted lines, through to the typescript and transition, they are virtually unchanged, and the placement - after drawing the line - hardly varies (JJA 53: 29, 52, 59, 92). The only significant change comes in the published edition, where it is moved to the centre of the page, rather than set alongside the text.

Of course, the published version introduces another major difference: marginalia and footnotes. As Joyce told Frank Budgen,

the technique here is a reproduction of a schoolboy's (and schoolgirl's) old classbook complete with marginalia by the twins, who change sides at half time, footnotes by the girl (who doesn't), a Euclid diagram, funny drawings, etc.

Letters I 405-6

The marginalia and footnotes were first added in the early 1930s to leftover proofs of Tales Told of Shem and Shaun, but they didn't appear in print until Storiella as She is Syung, a deluxe edition of the beginning and end of the "Nightlessons" chapter, which was printed with Lucia Joyce's hand-coloured capitals in 1937 and with the right-hand marginalia in red. Interestingly, in Storiella the "funny drawings" in Issy's final footnotes are printed before the nightletter. This might be because there wasn't room to print the letter on the lefthand page, but we see the same arrangement in the transition proofs (July 1935, JJA 53:400), where there clearly would have been room to print the letter above the footnotes, and Joyce could have marked the change. This might not seem to matter, since the footnotes still comment on "Cush" and "Geg", Irish for five and ten, in the list of numerals ( $F W 308.9,14)$, but it does make a difference because positioning the footnotes at the end softens the tone of the nightletter and allows Issy's "drawings on the line" to draw a line under the chapter, just as the half-time monologue ends "you must, how, in undivided reawlity draw the line somewhawre".

There is an intriguing story behind Issy's doodles. Joyce could have drawn them himself, as he did in the first draft (JJA 53: 281), but instead, he asked a child to draw them for him. In Joycean Murmoirs, Fritz Senn recalls a conversation with Hans von Curiel, a well-known figure in Zurich's theatrical scene. 
Curiel told Senn "that Joyce called on him one night and requested a childish drawing... Joyce needed a genuine girl's drawing, and it was done by Hans von Curiel's daughter, significantly named Lucia". ${ }^{15}$

It would be nice to know whether Lucia Curiel also drew the symbols or "sigla" ( $F W$ 32.14, 119.19) in the "Doodles family" footnote $(F W$ 299.F4). To my eye they are indistinguishable from those in Joyce's first draft (JJA 53: 220), or the hundreds of sigla Joyce drew in his notebooks and letters. ${ }^{16}$ Joyce refers to these in a famous letter to Harriet Shaw Weaver, dated March 24 1924:

In making notes I used signs for the chief characters. It may amuse you to see them so I shall write them on the back of this.

m (Earwicker, H C E by moving letter round)

$\Delta \quad$ Anna Livia

ᄃ Shem-Cain

$\wedge$ Shaun

S Snake

$P \quad$ S. Patrick

T Tristan

$\perp$ Isolde

$\times$ Mamalujo

口 This stands for the title but I do not wish to say it yet until the book has written more of itself.

$L I 213$

As Roland McHugh and others have observed, many of the sigla were originally based on letters, like the Snake, Patrick, Tristan or the rotated E of Earwicker. Issy's siglum began as a capital I before being truncated to mirror T; Shem's sign is a stylized C for Cain; Shaun's hat or carat siglum is an A minus the bar, just as ALP's delta can be read as an amputated A, missing the legs. Shem's sign is also like HCE's, minus the bar, just as Shaun's is an open delta, with no base.

These explanations are almost certainly correct, and I am not proposing that we reject them, but they don't tell the whole story. For one thing, Joyce moved away from standard letters, seeking a unique set of symbols for his characters. Little over two years after describing the sigla to Weaver, Joyce asked her

What have you learned in the hills about $\mathrm{m}, \Delta, \mathbf{C}, \wedge, \mathbf{T}, \perp \dashv \vdash \bigcirc \bigcirc$ etc.? $L I 242$

15 Fritz Senn, Joycean Murmoirs, ed. Christine O'Neill (Dublin: Lilliput Press, 2007), 48.

16 See, for instance, the first drafts of I.6 (JJA 47:2, 28). 
The only alphabetical letter left in this list is T, which may already be regarded as a rotation of the Issy siglum. In another letter, Joyce explains that the sigla served as memory aids, to stop his "brains from falling about" as he glanced back through his endless notebooks, looking for material to elaborate his avatars (Letters I 216). For this purpose, it was essential that they should stand out visually from ordinary letters. In this respect, as Finn Fordham notes, they are like Joyce's revision marks, which were also intended to stand out from his autograph manuscripts, so as to be immediately recognizable as corrections and additions. Fordham demonstrates a number of further similarities, including a selection of revision symbols, drawn from across the archive, looking suspiciously like the sigla: ${ }^{17}$

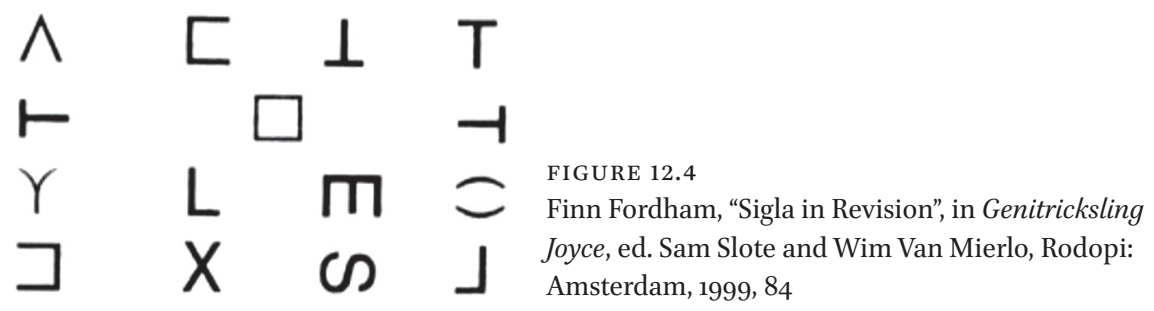

Joyce incorporated some of these marks directly into the Wake, as though to show that the letter and the book are always in revision. Likewise, by printing Issy's "Doodles family" footnote, Joyce brings prepublication symbols into the text, foregrounding the process of composition. We see both these aspects in 1.5, where holes forked in the letter resemble square brackets and the carat sign $\wedge$, clearly related to Shem and Shaun's sigla ( $F W$ 124.9-11), especially when Shaun the Post appears as "Hans the Curier" ( $F W$ 125.14: Hans is Dutch for Shaun; "Curier" combines curious, Curiel and courier). The allusion to Hans (von) Curiel connects these sigla to Issy's doodles, and the HCE and ALP sigla, introduced a few pages earlier:

the initials majuscule of Earwicker: the meant to be baffling chrismon trilithon sign $\mathbf{m}$, finally called after some his hes hecitency Hec which, moved contrawatchwise, represents his title in sigla as the smaller $\Delta$, fontly called following a certain change of state of grace of nature alp or delta.

$F W 119 \cdot 16-21$

17 Finn Fordham, "Sigla in Revision", in Genitricksling Joyce, ed. Sam Slote and Wim Van Mierlo (Rodopi: Amsterdam, 1999), 84. 
The passage is familiar, but an important aspect seems to have been overlooked. The paragraph in which Joyce first introduces the $m$ and $\Delta$ sigla into Finnegans Wake is preceded by the self-reflexive aside "strictly between ourselves there is a limit to all things" ( $F W 119.8-9)$. This limit, drawing a line above the paragraph, links the sigla in I.5 to those in II.2, where mathematical limits stand for sexual union and the moment of conception (both biological and intellectual). This association can be traced back almost to the beginning of the "Triangle", or A.M.D.G.-L.D.s. section $(F W 282.5-304.4$; see, e.g., $F W 284.8-12)$, reaching its "limitsing... tendency" with Issy's "Doodles family" footnote $(F W$ 298.26-299 F4).

Titled "The Muddest Thick That Was Ever Heard Dump", this section was first published in Tales Told of Shem and Shaun (1929), with a preface by C.K. Ogden, who translated Wittgenstein's Tractatus Logico-Philosophicus, as well as the end of "Anna Livia Plurabelle" (into BASIC). According to Caresse Crosby, who published the collection, Joyce asked Ogden "to comment, as a mathematician, upon the structure of Finnegans Wake, which he insisted was mathematical" ( JJ 627). More linguist and philosopher than mathematician, Ogden responded by pointing out "two main tendencies" in Finnegans Wake: the Rabelaisian, or carnavelesque, on the one hand; and the logico-mathematical "tradition which began with Bishop Wilkins [credited with inventing binary code] and Leibniz ... through Zamenhof [inventor of Esperanto] and C.S. Peirce, to the makers of the latest nomenclatures which are again revolutionizing the sciences". 18

This reference to the logic of the Wake is striking, particularly if Ogden was writing at Joyce's behest, like Gorman, Gilbert and the authors of Our Exagmination (also published in 1929). As noted, the sigla were originally derived from letters: HCE's "baffling chrismon trilithon" m simply rotates Earwicker's "initials majuscule" ( $F W$ 119.16-18), while $\Delta$ is a capital Greek delta. However, the characters themselves are clearly symbolic: river deltas are said to derive from the triangular shape of the letter, often figured as the source of life, and Earwicker's oracular siglum may be related to a capital Epsilon inscribed on the omphalos at Delphi. ${ }^{19}$ These symbols are also significant in logic and

18 James Joyce, Tales Told of Shem and Shaun (The Black Sun Press: Paris, 1929), xiv.

19 See Maud Ellmann, "Polytropic Man: Paternity, Identity and Naming in The Odyssey and A Portrait of the Artist as a Young Man", in Derek Attridge and Daniel Ferrer, eds. PostStructuralist Joyce: Essays from the French (Cambridge: Cambridge University Press, 1984), 73-104, and William Nickerson Bates, "The E of the Temple at Delphi", American Journal of Archaeology 29.3 (Jul.-Sep. 1925), 239-46. According to Bates, in the first century CE, three Es adorned the temple of Apollo: one in wood, one in stone and one in bronze. Bates notes that Delphic coins of that period show a large Epsilon on the east façade of the 
mathematics. For instance, the variables delta and epsilon are used to define mathematical limits, a meaning that seems to be in play when "the smaller $\Delta$, fontly" - that is, $\delta$ - measures a rate of "change" or gradient $(F W$ 119.19-20).

Whilst $\boldsymbol{m}$ is derived from Earwicker, a Greek capital, like $\boldsymbol{\Delta}$, the symbols are rotated into unfamiliar forms, like Issy's siglum or the Fs in "'race to trace?" and " $F$ न a a gaze" $(F W 18.36,266.22)$. HCE's siglum appears in all four rotations:
Ш $(F W 6.32)$
E? $\quad(F W 51.19)$
m (FW 119.17)
$\exists ! \quad\left(F W_{36.16)}\right.$

From a logical point of view, the latter is particularly significant. McHugh's explanation that HCE puts his right fist in the crook of his bent left elbow to make a backwards $\mathrm{E}$ is on the right lines, but I think Joyce is probably describing the bras d'honneur or Italian salute, roughly equivalent to a raised middle finger, so that "by ancientist signlore his gesture" has a clear meaning $(F W$ 36.15-16).

But by the newest signlore it also has a precise meaning: in logic, $\exists$ is the symbol for the existential quantifier, meaning there is an $\mathrm{x}$ such that... In Whitehead and Russell's nomenclature, $\exists$ ! means that the class $\alpha$ is non-empty,

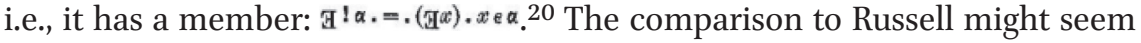
fanciful, but Joyce had a copy of Russell's Principles of Social Reconstruction in his Trieste library, he noted Russell's $A B C$ of Relativity in VI.B.19-73, and he took extensive notes on Russell's Introduction to Mathematical Philosophy for "Ithaca", returning to these notes when he wrote "Nightlessons".

Although Russell's Introduction to Mathematical Philosophy is written for lay readers, it is actually an advanced introduction to the latest work in modern logic (Russell, like Gottlob Frege, believed that mathematics was logic). Russell tries to avoid symbolic notation, but cannot do so entirely - the section on transfinite mathematics introduces Cantor's $\aleph_{0}$, for instance, which Joyce copied six times. Other passages Joyce made notes on refer to Principia Mathematica, Frege and Wittgenstein. Given Joyce's interest in Russell, Ogden's preface to

temple at Delphi. He mentions the discovery of a stone omphalos in the inner sanctuary of the temple in 1913 by Fernand Courby, bearing the inscription $\pi \pi \wedge$, which he interprets as the mysterious Epsilon (rotated forwards, like HCE), followed by Gamma and alpha, spelling E-Ga, the Greek earth goddess, as in Ga-Tellus. Rotated on its back (as in FW 6.32), the HCE symbol is also associated with the Chinese ideogram 山 meaning mountain (see $L I 250$ ), the Hebrew letter $\boldsymbol{w}$ (shin or shen) and the figure of Osiris lying on his back (see FWEET).

20 Alfred North Whitehead and Bertrand Russell, Principia Mathematica (Cambridge: Cambridge University Press, 1910), ${ }^{*} 24.03$. 
Tales Told of Shem and Shaun, and an allusion to "Die Welt ist alles, was der Fall ist", the first line of Wittgenstein's Tractatus (translated by Ogden), in "the world, mind, is, was and will be writing its own wrunes for ever" $\left(F W 19.35^{-36}\right)$, there can be little doubt that Joyce was aware of mathematical logic, and some probability that he glanced through these or similar works. If so, he would have encountered page after page of obscure signs and symbols - work that was being hailed as the greatest philosophy of the day, but which was almost unintelligible without learning its symbolic notation. Russell's fame may have comforted Joyce that his book would find its audience too, for most readers greet the Wake with similar incomprehension, despite its formidable reputation and its many signs of order and precision. In any case, the analogy is intriguing, for Finnegans Wake has its own symbolic logic, developing a seemingly hermetic symbolism (the sigla) to create a new kind of character, at once general and precise: "THE PARTICULAR UNIVERSAL" ( $\left.F W_{260} \mathrm{R}_{3}\right)$.

Whether or not Joyce read Principia Mathematica, the similarities between symbolic logic and the sigla of Finnegans Wake are worth considering. I have already mentioned Russell's $\exists$ !, a permutation of HCE. The turnstile stroke, $\vdash$, used by Peirce, Frege, Russell and Wittgenstein for assertion, is identical to Issy's siglum in one of its aspects; the $V$ sign Russell uses for the universal class is often written $\forall$ or $\nabla$, an inverted delta, or "nabla"; ${ }^{21}$ the carat-shaped $\Lambda$ for the Null class is the same symbol Joyce uses for Shaun; and Shem's $\boldsymbol{\square}$ symbol, derived from $\mathrm{C}$ (for Cain), is like a square bracket, denoting the scope of a function. These correspondences might be accidental, but it is equally plausible that Joyce was responding to symbolic logic, for the symbols are commonplace and readily intelligible - they all figure in Whitehead and Russell's brief, plain English summary of *24, "The Universal Class, The Null Class and the Existence of Classes", for instance.

Following this logic, HCE is associated with the assertion of existence, as either an individual or pluralized being, while ALP is an ill-including figure of universality - both of which have some relevance to Finnegans Wake. As Russell proves in his Introduction to Mathematical Philosophy, the existential quantifier and the universal quantifier can each be defined in terms of the other, so that universality and particularity are interrelated, ${ }^{22}$ like ALP and HCE. Of course, their roles and relationships are more complex than this, and

21 William Hamilton, an Irish mathematician, devised a new symbol for differentiation: $\triangleleft$. Later, this was replaced by an inverted delta, called nabla, after the Greek word for harp. Joyce alludes to "Rovinghamilton['s]" "nibbleh" in II.2 (FW 300.18-28), and we find the same figure beside "the portal" in vi.B.14.138.

22 Bertrand Russell, Introduction to Mathematical Philosophy (London: George Allen \& Unwin, 1919), 160. 
I wouldn't want to reduce them to logical operators, but there are marked similarities between the symbols of formal logic and Joyce's characters - in the original sense of characters as graphic marks or inscriptions. In "The Study of Languages", Joyce contends that literature, associated with arithmetic, is, "in its Grammar and Characters", a "science" ( $\left.C W_{2} 6\right)$. Returning to the fresco, he means that Grammar is the first of the earthly sciences, and its letters, or characters, are akin to mathematical symbols - a remarkably prescient observation, for, whether deliberate or not, the sigla of Finnegans Wake are akin to logical symbols, and whatever their various functions may be, the logic of the "Doodles family" underlies the logic of the Wake. 